\title{
Maxime Decout, Écrire la judéité. Enquête sur un malaise dans la littérature française
}

\section{Elena Quaglia}

\section{Q OpenEdition}

1 Journals

\section{Edizione digitale}

URL: http://journals.openedition.org/studifrancesi/1459

DOI: $10.4000 /$ studifrancesi. 1459

ISSN: 2421-5856

\section{Editore}

Rosenberg \& Sellier

\section{Edizione cartacea}

Data di pubblicazione: 1 décembre 2015

Paginazione: 630-631

ISSN: 0039-2944

\section{Notizia bibliografica digitale}

Elena Quaglia, «Maxime Decout, Écrire la judéité. Enquête sur un malaise dans la littérature française», Studi Francesi [Online], 177 (LIX | III) | 2015, online dal 01 décembre 2015, consultato il 13 janvier 2021. URL: http://journals.openedition.org/studifrancesi/1459; DOI: https://doi.org/10.4000/studifrancesi. 1459

Questo documento è stato generato automaticamente il 13 janvier 2021.

\section{(c) $(1) \ominus$}

Studi Francesi è distribuita con Licenza Creative Commons Attribuzione - Non commerciale - Non opere derivate 4.0 Internazionale. 


\title{
Maxime Decout, Écrire la judéité. Enquête sur un malaise dans la littérature française
}

\author{
Elena Quaglia
}

\section{NOTIZIA}

MAXIME DECOUT, Écrire la judéité. Enquête sur un malaise dans la littérature française, Seyssel, Champ Vallon, 2015, pp. 304.

1 Lo studio di Maxime Decout ripercorre la storia intellettuale e letteraria del concetto di judéité, termine coniato da Albert Memmi per indicare la relazione soggettiva con l'identità ebraica, al di fuori di ogni dimensione religiosa. Il critico analizza le differenti ripercussioni e risonanze della «question juive» a partire dall'inizio del xx secolo, in primo luogo nell'opera di scrittori di origine ebraica, quali André Spire, Albert Cohen, Élie Wiesel, Romain Gary, Edmond Jabès, Georges Perec e Patrick Modiano; tuttavia, egli non dimentica di mostrare come le differenti visioni dell'identità ebraica siano rielaborate in un contesto complesso, fatto di dialoghi e di scambi, nel quale trovano il loro posto anche scrittori antisemiti come Céline, o filosemiti come Marguerite Duras e Maurice Blanchot.

2 In questo modo, non solo Decout dà forma a una sintesi delle scritture della judéité finora assente nel panorama critico, ma rimette coraggiosamente in discussione l'intero canone letterario francese alla luce di una questione disturbante ma continuamente presente. In particolare, due snodi storici mettono al centro la problematica dell'identità e della memoria ebraica nei suoi rapporti etici e politici con la Francia e più in generale con l'umanità: l'Affaire Dreyfus e Auschwitz.

Il primo capitolo è dedicato alla «renaissance juive» degli anni Venti, «qui ne fut pas un mouvement littéraire à proprement parler, mais un regroupement de sensibilités» (p. 51), che riunì diversi scrittori in una riappropriazione dell'identità ebraica in seno alla 
nazione francese. Spire, Cohen, Fleg e altri cercarono così di trovare una conciliazione tra una judéité finalmente emersa sulla scena politica con l'Affaire Dreyfus e l'universalismo repubblicano francese che non vollero rinnegare.

4 Molto diverso è lo scenario post-genocidario al quale Decout dedica la maggior parte del suo studio, con alcuni brevi capitoli monografici sui differenti autori, ma soprattutto con analisi comparate che sovrappongono costantemente all'esame dei testi letterari una contestualizzazione storica e filosofica. La memoria ebraica è al centro di costanti riconfigurazioni, poiché non è forgiata solo dai testimoni, ma vi si confrontano anche scrittori che non sono reduci dai campi e la cui eredità culturale ebraica è pressoché assente: infatti, come afferma Decout, la «judéité n'est en effet, pour ces générations d'écrivains, ni religieuse, ni spirituelle. Elle est tout simplement historique» (p. 163).

5 Lo studio di Decout dimostra la sua originalità soprattutto nello studio degli scrittori filosemiti, veri e propri «passagers clandestins» (p. 171) dell'identità ebraica, spesso influenzati da una visione essenzialista della judéité, legata ai concetti di alterità e di erranza, centrali nel pensiero di Levinas, di Derrida, di Lyotard.

6 Il lungo capitolo conclusivo traccia infine una sintesi dei mutamenti nel campo storico e intellettuale negli ultimi decenni, in particolare legati all'emergere di nuove forme di antisemitismo, più subdole e meno riconoscibili. Inoltre, la letteratura della judéité deve confrontarsi con un «dovere di memoria» divenuto invadente e trovare nuovi percorsi per mettere in scena la propria ricerca identitaria.

7 Cosa hanno apportato la memoria e l'identità ebraica a un secolo di letteratura e di pensiero, scandito da eventi storici che le hanno rimesse di volta in volta in discussione? La scommessa riuscita del saggio di Maxime Decout è quella di fornire una risposta a questa domanda mostrando i diversi percorsi intrapresi dalle scritture della judéité e definendone allo stesso tempo il radicamento in un'epoca storico-letteraria ben determinata, secondo uno sforzo di sintesi diacronica. Il critico ha così fornito una nuova prospettiva sulla letteratura francese del xx secolo, che si rivela costantemente attraversata dalla questione della memoria ebraica. 